\title{
Cultural Cognition and Ideological Framing Influence Communication About Zoonotic Disease in the Era of COVID-19
}

\section{OPEN ACCESS}

Edited by:

Ulrike Felt,

University of Vienna, Austria

Reviewed by: Sibo Chen,

Ryerson University, Canada Justin Reedy,

University of Oklahoma, United States

*Correspondence:

Justin M. Beall

jmbeall@ncsu.edu

Specialty section:

This article was submitted to

Science and Environmental

Communication,

a section of the journal

Frontiers in Communication

Received: 23 December 2020

Accepted: 12 May 2021

Published: 31 May 2021

Citation:

Beall JM, Casola WR, Peterson MN, Larson LR, Carr WA, Seekamp E, Stevenson KT and Jackson SB (2021) Cultural Cognition and Ideological

Framing Influence Communication About Zoonotic Disease in the Era of COVID-19.

Front. Commun. 6:645692. doi: 10.3389/fcomm.2021.645692
Justin M. Beall ${ }^{1 *}$, William R. Casola ${ }^{2}$, M Nils. Peterson ${ }^{2}$, Lincoln R. Larson ${ }^{1}$, Wylie A. Carr ${ }^{3}$, Erin Seekamp ${ }^{1}$, Kathryn T. Stevenson ${ }^{1}$ and S Brent Jackson ${ }^{1}$

${ }^{1}$ Department of Parks, Recreation, and Tourism Management, College of Natural Resources, North Carolina State University, Raleigh, NC, United States, ${ }^{2}$ Fisheries, Wildlife and Conservation Biology Program, Department of Forestry and Environmental Resources, College of Natural Resources, North Carolina State University, Raleigh, NC, United States, ${ }^{3}$ U.S. Fish and Wildlife Service, Atlanta, GA, United States

The efficacy of science communication can be influenced by the cultural values and cognitions of target audiences, yet message framing rarely accounts for these cognitive factors. To explore the effects of message framing tailored to specific audiences, we investigated relationships between one form of cultural cognition-political ideology-and perceptions about the zoonotic origins of the COVID-19 pandemic using a nationally representative Qualtrics XM panel $(n=1,554)$ during August 2020. First, we examined differences in attitudes towards science (in general) and COVID-19 (specifically) based on political ideology. We found that, compared to conservatives and moderates, liberals trusted science more, were less skeptical of science, perceived greater risk from COVID-19, were more likely to believe in a wildlife origin of COVID-19, and were more likely to support restrictions on wildlife trade. Second, we examined the influence of cultural framing on the perceived validity of science related to COVID-19. Respondents were randomly assigned to one of three treatment groups: 1) a technocratic framing that highlighted feats of human ingenuity to overcome zoonoses; 2) a regulatory framing that highlighted regulations and expansions of protected areas for wild life as a means to prevent zoonoses, and 3) a control article about traffic lights with no cultural framing. After reading the initial framing article, all three groups read the same fictional, yet factually accurate, 'Nature Science study' generated by the authors. An OLS regression model revealed a significant interaction between the technocratic framing and political ideology. Relative to the control group, the technocratic framing slightly increased perceived validity of the Nature Science study for conservatives, significantly lowered perceived validity for liberals, and had no impact on moderates. We did not detect any significant interaction between framing and political ideology for the regulatory framing. Findings of this study highlight the need to account for cultural cognitions when communicating about COVID-19 and other zoonotic diseases. Communication strategies carefully designed to resonate with ideologically diverse audiences may ultimately lead to bipartisan support for actions required to promote "One Health" approaches that reduce the impacts of zoonoses on human and environmental health.

Keywords: coronavirus-COVID-19, message framing, one health, political ideology, science communication, wildlife, zoonoses 


\section{INTRODUCTION}

The COVID-19 pandemic has highlighted the critical need to improve communication about zoonotic disease to mitigate global threats to the health, safety, and financial stability of the global community, including both humans and wildlife (Daszak et al., 2000; Cunningham et al., 2017; Henig, 2020; Nuwer, 2020). The World Health Organization (WHO) define zoonotic diseases as "any disease or infection that is naturally transmissible from vertebrate animals to humans" (World Health Organization, 2020); a definition that encompasses the COVID19 pandemic. To be effective, communication about zoonotic disease may need to account for cultural values and worldviews. The cultural cognition thesis suggests individuals process information through the filter of their worldviews and accept or reject facts based on their beliefs about how social systems should function (Kahan et al., 2010). For instance, those with hierarchical and individualistic worldviews tend to downplay environmental risks, as they believe addressing them would threaten hierarchical social structures and restrict the free market (Kahan et al., 2008). In contrast, those with egalitarian and communitarian worldviews are more likely to perceive risk from environmental issues and support environmental regulations, as they interpret unrestricted markets as sources of inequality within society (Douglas and Wildavsky, 1983; Kahan et al., 2008). Worldviews are closely tied to political ideology, particularly in the United States, where conservatives tend to adopt individualistic and hierarchical worldviews and liberals tend to adhere to communitarian and egalitarian ones (Wildavsky, 1987; Gastil et al., 2011; van der Linden, 2016). Furthermore, political polarization on key issues has magnified ideological differences based on party affiliation within the United States (Pew Research Center, 2017).

Political polarization has been particularly evident in the context of the COVID-19 pandemic, as news coverage regarding the lethal zoonotic disease has helped to fuel a partisan divide in perceptions of the pandemic, its causes, and its consequences (Hart et al., 2020). Thus, uncertainty surrounding the COVID-19 pandemic can be used as a tool by political elites to reduce trust in science and diminish support for science-based policy (Kreps and Kriner, 2020). Such tactics might further erode trust in science, a trend that is particularly prominent among conservatives (Gauchat, 2012; Funk et al., 2019), leading to higher levels of polarization. Thus, it has become urgent to investigate the influence of political ideology on beliefs about COVID-19 and explore the ability of culturally responsive communication to increase the efficacy of messaging related to zoonotic disease. It is especially important to implement effective communication during pandemics, as rapidly evolving knowledge may lead to widespread misinformation (Vraga and Jacobsen, 2020). Further, better communication can help mitigate future zoonotic disease outbreaks similar to COVID-19 by building public support for proactive wildlife management actions and policy changes needed to reduce disease risks (Hanisch-Kirkbride et al., 2013) and promote biodiversity conservation (Jacobson et al., 2019). This integrated approach reflects a "One Health" conceptualization of zoonotic disease communication where humans, wildlife, and the environment all become part of the story (Lu et al., 2016; Centers for Disease Control, 2020; Zinsstag et al., 2020). However, the extent to which these new approaches influence the growing polarization of perspectives remains unclear.

Lapinski et al. (2015) called for more testable hypotheses about how different human cognitions influence the efficacy of One Health message framing about zoonotic disease. To address this knowledge gap, we investigated how conservatives, moderates and liberals in the United States differed in their attitudes toward science and wildlife diseases, and how political ideology shaped the efficacy of science communication about COVID-19. To this end, we compared general beliefs about science, specific beliefs about the zoonotic origins of COVID-19, and responses to different types of message framing (focused on technocratic vs. regulatory solutions to prevent zoonoses) among three groups with different political ideologies. Our first set of hypotheses focused on investigating different beliefs and perceptions about science and the pandemic based on political ideology:

H1: Compared to conservatives, liberals and moderates will exhibit more trust in science.

$\mathrm{H} 2$ : Compared to conservatives, liberals and moderates will be less skeptical of science.

H3: Compared to conservatives, liberals and moderates will perceive greater risk to human health, safety, and prosperity associated with COVID-19.

H4: Compared to conservatives, liberals and moderates will express more belief that COVID-19 originated in wildlife.

H5: Compared to conservatives, liberals and moderates will express more support for actions to regulate wildlife trade tied to zoonotic disease transmission.

Our second set of hypotheses focused on examining the influence of different message frames, designed to resonate with certain cultural worldviews (i.e., political ideologies), on the perceived validity of science communication about the zoonotic origins of the COVID-19 pandemic and potential management responses.

H6: Science communication about the zoonotic origins of COVID-19 primed with a technocratic framing (focusing on human ingenuity and technological solutions to zoonoses) will be perceived as more valid among conservatives and less valid among liberals and moderates.

H7: Science communication about the zoonotic origins of COVID-19 primed with a regulatory framing (focusing on regulations to promote the shared health of humans and wildlife) will be perceived as more valid among liberals and moderates, and less valid among conservatives.

\section{BACKGROUND ON ZOONOSES AND COMMUNICATION RESPONSES}

As defined by the Centers for Disease Control (CDC), emerging infectious diseases (EIDs) are "those whose incidence in humans has increased in the past two decades or threaten to increase in the near future" Centers for Disease Control (2018). Zoonoses, a 
class of EIDs that emerge from wildlife and become infectious to humans, may pose the greatest threats to human health and wellbeing (World Health Organization, 2020). Several notable human diseases have emerged from wildlife including SARS, Hendra virus, Nipah virus, Ebola, HIV, Malaria, and COVID-19 (Evans et al., 2020). Zoonoses can be deadly or have lasting effects throughout the lifetime of people who are infected. For instance, from 2017 to 2018, Malaria had an estimated death toll of 405,000-416,000 despite continued global efforts to combat the mosquito-borne disease (World Health Organization, 2019). HIV/AIDs, a chronic disease affecting the immune system that originated in wild primates, claimed the lives of an estimated 690,000 individuals in 2019 (UNAIDS, 2020). Encephalitis, acute respiratory distress syndrome, and depression are just a few of the symptoms associated with the Nipah virus, which originated in fruit bats and produced a mortality rate of about $70 \%$ in humans when it first spread in Bangladesh and India (Ang et al., 2018). COVID-19 is a recent zoonosis that likely originated from a bat (Andersen et al., 2020) and spread through the Huanan seafood market, which sells various types of live wildlife including poultry, fish, marmots, pangolins, and bats, among others (Wu et al., 2020; Zhou et al., 2020). In 2020, the death toll for COVID-19 exceeded 1.7 million globally (Centers for Systems Science and Engineering, 2020; Dong et al., 2020), and early research has revealed significant and persistent damage to cells within the lungs from the virus, which may explain chronic symptoms for some individuals (Bussani et al., 2020). These examples illustrate the massive losses of life and impacts to human health associated with zoonoses at a global scale.

In addition to these health impacts, zoonoses also pose a major threat to the world economy (Cunningham et al., 2017). Findings suggest that the economic impacts of zoonoses reach into multiple sectors of the global economy, causing losses estimated in the billions of dollars by effecting services worldwide including agriculture, tourism, commerce, and transportation (Fonkwo, 2008). For instance, the cost of the global AIDs response for 2020 is estimated to be $\$ 26$ billion (UNAIDS, 2020). Other major outbreaks including SARS, Ebola, and H1N1 have cost economies worldwide a combined \$138 billion (Global Preparedness Monitoring Board, 2019). The COVID-19 pandemic is predicted to have a total cost of $\$ 16$ trillion when factoring in loss of human life, direct economic impacts, impacts to mental health, and long-term health impacts while assuming that the virus will be well contained by Fall 2021 (Cutler and Summers, 2020).

Beyond the severe consequences of zoonoses for humans, these diseases also present a direct threat to wildlife species and biodiversity on a global scale (Daszak et al., 2000; Corlett et al., 2020; Morand, 2020). For example, George et al. (2015) found that $47 \%$ of avian species in a sample of a quarter million birds tested positive for the zoonosis West Nile Virus, which caused significant mortality in species that failed to build immunity over time. Zoonoses that emerge from wildlife may transfer to humans and "spillover" back into susceptible wildlife populations, as evidenced by the transfer of the zoonotic parasite Giardia from humans to wildlife species such as beaver and muskoxen (Jenkins et al., 2013; Thompson, 2013). Given a lack of immunity to COVID-19 within North American bats, spillover from humans into populations of bats poses a potential threat to bat conservation (Olival et al., 2020). Recently, COVID-19 has spilled over into populations of mink in Utah, United States, and Denmark, resulting in mass culling and heavy economic losses (Cahan, 2020; Munnink et al., 2020). Spillover of zoonoses also occurs from populations of wildlife to domesticated animals and vice-versa, often incentivizing the elimination of wild species that carry the disease (Nugent, 2011). For instance, Bison herds in Yellowstone National Park have been culled in order to prevent the spread of Brucellosis (Brucella abortus) to domestic livestock, thus negatively impacting bison conservation within the park (White et al., 2011). These are only a few of the many examples of zoonoses that simultaneously affect both humans and wildlife.

For all of these reasons, growing global efforts to research and improve science communication regarding zoonoses have increasingly focused on the One Health perspective (Zinsstag et al., 2020). One Health is a "collaborative, multisectoral, and transdisciplinary approach-working at the local, regional, national, and global levels - with the goal of achieving optimal health outcomes recognizing the interconnection between people, animals, plants, and their shared environment" (Centers for Disease Control, 2020). This perspective illuminates the interconnected nature of human, environmental, and animal health, and suggests that addressing zoonoses requires broad conservation policies that encourage human behavior change and designate protected areas for wildlife (Jenkins et al., 2015; BonillaAldana et al., 2020).

Effective communication that influences risk perceptions of zoonoses and targets behavior change is a key element of the One Health approach (Decker et al., 2012), and the efficacy of such communication has been supported by prior research (Triezenberg et al., 2014; Lu et al., 2016). In one study focused on bovine tuberculosis (TB) in white-tailed deer (Odocoileus virginianus), persuasive communication materials mailed to hunters increased the perceived risk from TB, increased reported behavioral intentions to hunt the species, and increased the perception that other hunters were carrying out behaviors to combat TB (Triezenberg et al., 2014). Another study found that persuasive communications that conveyed the risk of rabies from bats, while also highlighting their ecological benefits, were able to influence intentions to adopt recommended rabies prevention measures without stigmatizing bats (Lu et al., 2016). Studies such as these are useful because effective wildlife communication can help members of the public understand risk, which in turn has been shown to influence support for wildlife disease management (Hanisch-Kirkbride et al., 2013). Such studies are also needed to avoid inciting bias against specific species, inspiring fear of natural areas, and eroding support for conservation (Decker et al., 2012; Buttke et al., 2015). For example, misinformed individuals who see bats as the cause of the COVID-19 pandemic may wish to enact retribution or withdraw support for bat conservation (MacFarlane and Rocha, 2020).

Cultural framing, or packaging information to appeal to an audience's worldviews, influences risk perception of some environmental issues and the perceived validity of science 
related to them (Kahan et al., 2008; Kahan et al., 2015). For example, with respect to climate change, a technocratic framing that emphasizes technological solutions and highlights the power of human ingenuity tends to resonate well with those who hold individualistic worldviews, whereas a regulatory framing that focuses on restrictions to markets and protections for the environment resonates well with those holding communitarian worldviews (Kahan et al., 2015). Political ideology operates similarly to worldviews, with both liberals and conservatives reacting negatively to scientific information that conflicts with their cultural worldviews. This dynamic is on display when predicting concern about genetically modified foods among liberals (Zimmerman and Eddens, 2018) and climate change skepticism among conservatives (Hamilton, 2015). Accounting for cultural worldviews, or political ideology as a more concrete manifestation of worldviews, appears to be crucial for effective communication about science topics. Cultural framing may therefore impact how people respond to communication about zoonotic diseases. For instance, framing that emphasized human responsibility for the emergence of Lyme disease and impacts of the disease in the near future created backlash among Republicans, who reported lower intentions to engage in proconservation behaviors after receiving the communication; yet, the same framing had no impacts on the conservation behavioral intentions of Democrats (Roh et al., 2015). Although the efficacy of One Health communication has been demonstrated (Lu et al., 2016; Lu et al., 2017), it is not clear how such messaging resonates or conflicts with individuals who hold different cultural worldviews or political ideologies. Our study used the COVID19 content to explore answers to this question.

\section{METHODS}

Institutional Review Board (IRB) approval was obtained before commencing the study. We collected a nationally representative sample of 1,554 United States residents through a Qualtrics XM survey panel during August 2020. In the Qualtrics XM panel potential respondents from across the United States sign up to participate in online surveys through the Qualtrics website. Researchers set certain criteria for a sample (in our case, a representative sample of the United States) and Qualtrics invites respondents to participate who meet the criteria. Qualtrics continues to collect data until quotas set by the researchers are filled, at which time the researchers can download the data for analysis. We chose to use a Qualtrics panel as it allowed for demographic quotas and, when compared to other online panel providers, came closest to a national probability sample in terms of demographic and political representativeness (Boas et al., 2018). Qualtrics also allowed for rapid data collection-a critical need in a COVID-19focused study. The panel for this study drew from a national pool (50 states and Puerto Rico) with demographic quotas for regions of the United States (South, West, Midwest, Northeast), race/ethnicity (White, Hispanic, Black, Asian), and age (18-34, $35-54,55+)$. Quotas were also set for the different treatment groups to ensure equal responses across groups. Though
Qualtrics panels have no true response rate, as the respondents are paid to complete the survey, they do provide an "incidence rate" that measures the amount of potential respondents who were deemed ineligible for participation. In this case, this included those under the age of 18 and those who we had already met demographic quotas for, resulting in an incidence rate of $60 \%$ of the total potential respondents.

Several scales were adapted from prior literature or, where not previously established, generated by the authors for the purposes of this study (Table 1). The scale used to assess the perceived risk of COVID-19 was adapted from Kahan et al. (2015). The trust in science and skepticism toward science scales were also adapted from previous literature (Gauchat, 2011; Nadelson et al., 2014). Two scales measuring beliefs about COVID-19 origins and attitudes toward wildlife trade were developed by the authors for this study. The measure used to assess respondents' perceptions of the validity of the hypothetical scientific study was adapted from Kahan et al. (2015). Reliabilities were assessed for each scale with the cutoff Cronbach's alpha $>0.70$ (Nunnally, 1978).

Political ideology was assessed using a 5-point scale, adapted from Casola et al. (2020), ranging from strong conservative to strong liberal. We chose to use political ideology rather than the more abstract constructs sometimes employed in the cultural cognition framework (e.g. communitarian and individualist) for three key reasons. First, research suggests cultural cognition closely parallels political ideology (Wildavsky, 1987; Gastil et al., 2011) and may be a means for explaining why individuals with different political ideologies differ in their views on topics (van der Linden, 2016). Second, initial research suggests that political ideology is particularly salient for driving polarization of COVID-19 topics (e.g. Calvillo et al., 2020; Hart et al., 2020). Thus, political ideology has more empirical support as a driver of attitudes toward COVID-19 than other measures of cultural worldview. Third, political ideology is more concrete and widely recognizable than the abstract measures of cultural worldview, which facilitates application of results.

We used a two-channel science communication strategy to assess how message framing influenced perceptions of the validity of a study related to the origins of COVID-19 (Kahan et al., 2015). To this end, we followed the approach of Kahan et al. (2015) and developed two fictional, but factually accurate, articles with message frames that contained the same channel 1 and a different channel 2 communication. Channel 1 (the first four paragraphs, the exact same in each treatment) focused on providing empirical information relevant to zoonoses. Channel 2 (the remaining paragraphs, differing by treatment) focused on unique appeals to specific cultural values. We also adapted a third control article from Kahan et al. (2015) with no cultural framings or channeled communication. The first group received a technocratically framed article designed to appeal to individualistic values, "Early detection and elimination, not additional wildlife regulations, needed to fight diseases like COVID-19" (Figure 1). The structure of this article was loosely based on the geoengineering framed article present in Kahan et al. (2015), but focused instead on technical aspects of 
TABLE 1 | Means, standard deviations, and Cronbach's Alpha for scale items $(n=1,554)$.

\begin{tabular}{|c|c|c|c|}
\hline Scale and item Description & Mean & Sd & Cronbach's alpha \\
\hline Trust in science & - & - & 0.83 \\
\hline To what extent do you agree with the following statements about science? ${ }^{a}$ & - & - & - \\
\hline TRUST1: Science and technology make life healthier, easier and more comfortable & 5.51 & 1.28 & - \\
\hline $\begin{array}{l}\text { TRUST2: Even if it brings no immediate benefits, scientific research is necessary and should be supported by the } \\
\text { government }\end{array}$ & 5.49 & 1.38 & - \\
\hline TRUST3: Overall, the benefits of scientific research have outweighed any harmful effects & 5.02 & 1.50 & - \\
\hline TRUST4: Most scientists want to work on things that will make life better for the average person & 5.42 & 1.35 & - \\
\hline To what extent do you disagree or agree with each of the following statements? ${ }^{b}$ & - & - & - \\
\hline TRUST5: We should trust the work of scientists & 5.24 & 1.29 & - \\
\hline TRUST6: We should trust that scientists are being honest in their work & 5.15 & 1.35 & - \\
\hline Skepticism toward science & - & - & 0.76 \\
\hline To what extent do you agree with the following statements about science? ${ }^{a}$ & - & - & - \\
\hline SKEP1: We depend too much on science and not enough on faith & 4.17 & 1.95 & - \\
\hline SKEP2: Science makes our way of life change too fast & 4.42 & 1.73 & - \\
\hline To what extent do you disagree or agree with each of the following statements? & - & - & - \\
\hline SKEP3: We cannot trust scientists because they are biased in their perspectives & 3.46 & 1.70 & - \\
\hline SKEP4: We cannot trust scientists to consider ideas that contradict their own & 3.76 & 1.69 & - \\
\hline Perceived risk from COVID-19 to human health and wellbeing & - & - & 0.82 \\
\hline To what extent do you disagree or agree with each of the following statements? ${ }^{b}$ & - & - & - \\
\hline RISK1: Diseases people catch from wildlife are increasing & 5.11 & 1.38 & - \\
\hline RISK2: Human activity is causing the threat of diseases people catch from wildlife to rise & 5.34 & 1.37 & - \\
\hline $\begin{array}{l}\text { RISK3: Unless steps are taken to counteract diseases people catch from wildlife, there will be bad consequences for } \\
\text { humans }\end{array}$ & 5.41 & 1.37 & - \\
\hline On a scale of 0-10 with 0 being "no risk at all" and 10 meaning "extreme risk," & - & - & - \\
\hline $\begin{array}{l}\text { RISK4: How much risk would you say diseases people can catch from wildlife pose to human health, safety, and } \\
\text { prosperity? }\end{array}$ & 5.47 & 1.25 & - \\
\hline Belief in a COVID-19 wildlife origin & - & - & 0.77 \\
\hline To what extent do you disagree or agree with each of the following statements? ${ }^{b}$ & - & - & - \\
\hline ORIG1: COVID-19 is a disease that originated in wild animals & 4.20 & 1.97 & - \\
\hline ORIG2: Diseases such as COVID-19 can be prevented by changing the way people interact with wildlife & 4.24 & 1.87 & - \\
\hline Attitudes toward restricting wildlife trade & - & - & 0.89 \\
\hline To what extent do you disagree or agree with each of the following statements? ${ }^{b}$ & - & - & - \\
\hline TRD1: All commercial sales of wildlife products should be stopped & 4.32 & 1.90 & - \\
\hline TRD2: All markets that sell live wild animals should be shut down & 4.68 & 1.91 & - \\
\hline TRD3: All markets that sell carcasses or meat from wild animals should be shut down & 4.58 & 1.94 & - \\
\hline TRD4: Wildlife products should not be transported between nations & 5.08 & 1.80 & - \\
\hline Perceived validity of nature science study & - & - & 0.61 \\
\hline With 0 meaning "completely unconvincing" to 10 meaning "completely convincing"a & - & - & - \\
\hline VALID1: In your view, how convincing was the Nature Science study on a scale of 0-10? & 5.46 & 1.31 & - \\
\hline To what extent do you disagree or agree with each of the following statements? ${ }^{b}$ & - & - & - \\
\hline VALID2: Computer models of diseases spread from wildlife are valid & 4.78 & 1.41 & - \\
\hline
\end{tabular}

${ }^{a}$ Recoded to 7-pt Likert scale.

'Likert scale 1 = "strongly disagree" to 7 = "strongly agree".

wildlife population management (Bosch et al., 2015; Grant et al., 2017). The second group received a regulatory framed article designed to appeal to communitarian values, "More Protected Areas for Wildlife and Stricter Regulations Needed to Fight Diseases like COVID-19" (Figure 2). This article's structure was loosely based on the anti-pollution article in Kahan et al. (2015), but instead focused on restrictions for wildlife trade and expansion of wildlife refuges as encouraged by the One Health approach to managing wildlife disease like COVID-19 (Bonilla-Aldana et al., 2020). Following the model in Kahan et al. (2015), individuals in the third control group received an article about traffic signals that was free of any information about COVID-19 that would activate cultural values (Figure 3). We randomly assigned respondents to one of these three treatments.
After reading the randomly assigned framing article (technocratic, regulatory, or control), all respondents read an article excerpt from a fictional, but factually accurate, scientific journal (Nature Science) about COVID-19 and the relationship between humans and ecosystem health (Figure 4). This article included factual information from Bonilla-Aldana et al. (2020), Mackenzie and Smith, (2020), and Rothan and Byrareddy (2020) regarding the wildlife origin of COVID-19, the risk to human health and wellbeing associated with the disease, and the potential economic losses from zoonoses such as COVID-19. This article lacked ideological framing, and we sought to reduce the perception of cultural meanings by specifically focusing on descriptive wording in this article. To do this, we avoided words and phrases that would obviously evoke cultural meanings, as suggested by Kahan et al. (2015). Respondents 


\title{
Scientists: Early detection and elimination, not additional wildlife regulations, needed to fight diseases like COVID-19
}

\section{New study finds current wildlife management practices will not prevent future diseases}

\author{
By Andrew Taylor
}

June 24th, 2020

WASHINGTON DC. Avoiding the worst effects of diseases that humans can catch from wildlife, such as COVID-19, will require a different approach, a group of expert scientists announced today. Countries should focus less on making new wildlife regulations and new protected areas for wildlife. Instead, new technologies that reduce the risk of wildlife giving humans diseases are needed.

The group, the American Academy of Wildlife Disease (AAWD), based this conclusion on a new study finding that the coronavirus (COVID-19) likely originated from a wildlife market in Wuhan, China, and that the threat of similar diseases emerging from wildlife markets and wildlife trade in the future is high.

The study was done by researchers from the Massachusetts Institute of Technology who were unaffiliated with AAWD and who published their findings earlier this year in the journal Nature Science.

"Before this study," said AAWD spokesman Dr. Alan M. Williams of Harvard University, "people believed diseases such as COVID-19 could be detected and stopped before they spread, but this scientific study in Nature Science shows that current strategies for protecting people from wildlife diseases will not be enough."

"Even with more rules at wildlife markets and more policing of wildlife trade," Dr. Williams told reporters, "the Nature Science study shows that the future risk of people catching diseases from wildlife is high."

The AAWD report states that the Nature Science study "supports only one conclusion: more rules for wildlife trade and more protected areas for wildlife are wasteful strategies." Instead, the report urges using technology to find diseases faster and remove wildlife that carry diseases.

"There are many technologies available to find and eliminate wildlife diseases," said Dr. Alan Williams. "Trained professionals can find diseases within wildlife populations with the highest risk of spreading to humans. Then wildlife populations with the diseases can be removed."

Developing these so-called "early detection" technologies, the AAWD report concludes, would not only be more effective than new rules and new protected areas for wildlife, but also spare consumers and businesses the economic costs associated with regulation of wildlife trade and lost opportunities for development on protected lands.

"Human beings have faced challenges from nature throughout history," Williams told reporters at a press conference. "We've never accepted defeat - we've always overcome them with ingenuity."

"Consider today's high-yield farming methods, the miracles of modern medicine, and the breathtaking feats of urban engineering," Williams stated. "Well, it's time for us to innovate our way out of another jam."
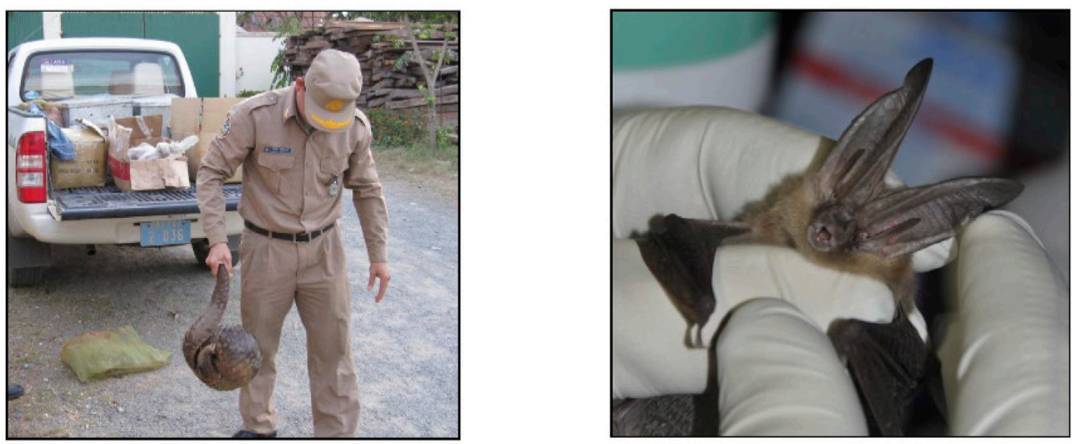

Technology-driven solutions for preventing wildlife diseases in humans. AAWD report proposes technological solutions to prevent future coronaviruses after study reports "a common exposure point for all of the infected individuals, the seafood market in Wuhan, China." Professionals can test for coronaviruses in the field (left) and extract and analyze samples in the lab (right) in order to track and eliminate wildlife that carry diseases. (Credit: AAWD report "Fighting Diseases from Wildlife: Technology, Not Regulation, Needed to Prevent Outbreaks.")

FIGURE 1 | Technocratic framing of COVID-19 science highlighting human ingenuity and technology as means to prevent and control the emergence and spread of zoonoses. Modeled after Kahan et al. (2015), information from Bosch et al. (2015) and Grant et al. (2017). Images obtained from Creative Commons. Left image: "Pangolin Rescue" by Wildlife Alliance is licensed under CC BY-SA 2.0. Right image: "Townsend's big-eared bat" by USFWS Headquarters is licensed under CC BY 2.0. 


\title{
Scientists: More Protected Areas for Wildlife and Stricter Regulations Needed to Fight Diseases like COVID-19
}

\author{
New study finds current wildlife management practices will likely be ineffective for preventing \\ future diseases
}

By Andrew Taylor

June 24th, 2020

WASHINGTON DC. Avoiding the worst effects of diseases that humans can catch from wildlife, such as COVID-19, will require countries to expand the land area protected for wildlife and make new regulations, a group of expert scientists announced today.

The group, the American Academy of Wildlife Disease (AAWD), based this conclusion on a new study finding that the coronavirus (COVID-19) likely originated from a wildlife market in Wuhan, China, and that the threat of similar diseases emerging from wildlife markets and wildlife trade in the future is high.

The study was done by researchers from the Massachusetts Institute of Technology who were unaffiliated with AAWD and who published their findings earlier this year in the journal Nature Science.

"Before this study," said AAWD spokesman Dr. Alan M. Williams of Harvard University, "people believed diseases such as COVID-19 could be detected and stopped before they spread, but this scientific study in Nature Science shows that current strategies for protecting people from wildlife diseases will not be enough."

"Even with more rules at wildlife markets and more policing of wildlife trade," Dr. Williams told reporters, "the Nature Science study shows that the future risk of people catching diseases from wildlife is high."

The AAWD report states that the Nature Science study "supports only one conclusion: the health and protection of wildlife is linked to the health of human beings." As a result, "the overall area of protected land for wildlife and the number of regulations on wildlife trade will need to increase a lot," the AAWD report concludes.

"World governments have a wide range of wildlife management tools at their command - including using tax money to protect land for wildlife, restricting wildlife trade, and limiting human activity in these protected areas," said Dr. Williams. "It's time to use them," he said.

Industrialized nations such as the United States and Great Britain have so far opposed these policies needed to prevent humans from catching diseases from wildlife because new rules and new protected land might hurt businesses and consumers. Creating new protected areas for wildlife and adopting stricter regulations as suggested by the AAWD would impose large costs, the report acknowledged.

"Yes, we will all need to make sacrifices," stated Williams in a press conference announcing the AAGS report. "Yet we are in this mess precisely because the residents of industrialized countries have, for decades, insisted on developing land and harvesting wildlife to achieve a standard of living that exceeds what the natural environment can support." Williams told reporters in Washington, D.C.
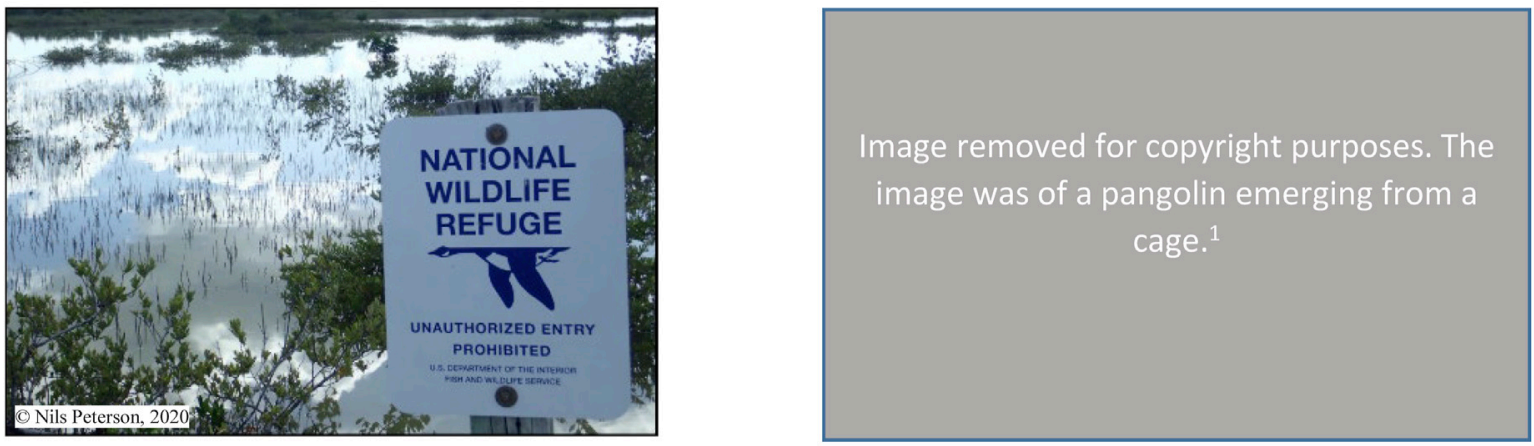

Protecting wildlife may lower risk of disease transmission to humans. A recent study suggests that wildlife markets and illegal wildlife trade create "hotspots" for diseases that people catch from wildlife, like COVID-19. The AAWD has called for stricter regulations on wildlife trade as well as more protected areas to help wildlife and improve the health of wildlife.

FIGURE2 | Regulatory framing of COVID-19 science highlighting the need for regulations and expansions of protected areas for wildlife to prevent the emergence and spread of zoonoses. Modeled after Kahan et al. (2015), information from Bonilla-Aldana et al. (2020). ' Link to removed image: https://www.gettyimages.com/detail/ news-photo/malayan-pangolin-is-seen-out-of-its-cage-after-being-news-photo/51341736?adppopup=true 


\title{
Traffic Signal Funds Required
}

Developers Must Put up Surety Bond

\author{
By Jeffery Cohen \\ Broomfield County Star June 15, 2020
}

A new Broomfield County policy will ensure that the next time a community needs a new traffic light to handle traffic associated with a commercial development, it will have the funds necessary to pay for it.

Developers who want to begin work on a new subdivision will be required to put up a surety bond, probably as much as $\$ 300,000$, said Dorothy Doyle, the county's traffic division director. Traffic signals range in price from $\$ 60,000$ for those strung on wires to $\$ 300,000$ for a sturdier mast arm signal.

The impetus for the requirement comes from six recent cases in which traffic signals ended up being needed at communities where the developer had finished building, or in which the county had not initially heard concerns about a light, Doyle said.

The county will be able to hold the surety well after the subdivision is built, Doyle said, adding that the developer will be required to notify the county as it nears completion.

"We've always required developers to defray costs associated with the impact of their projects on local traffic, so this is nothing out of the ordinary," Doyle said.

Kevin Bain, President of GL Homes, Inc., the largest developer in the county, said many of his company's developments qualify for a signal anyway, adding that it's an appropriate issue for the county to address.

"It's a safety issue for our residents," Bain said. "We don't have an issue whatsoever with posting the surety."

Harry Halman, chairman of the Broomfield Chamber of Commerce, said the new surety policy makes sense.

"I think that the new requirements of anticipating the need for a traffic light are very valid, because inadequate traffic control is likely to discourage shopping downtown," said Halman.
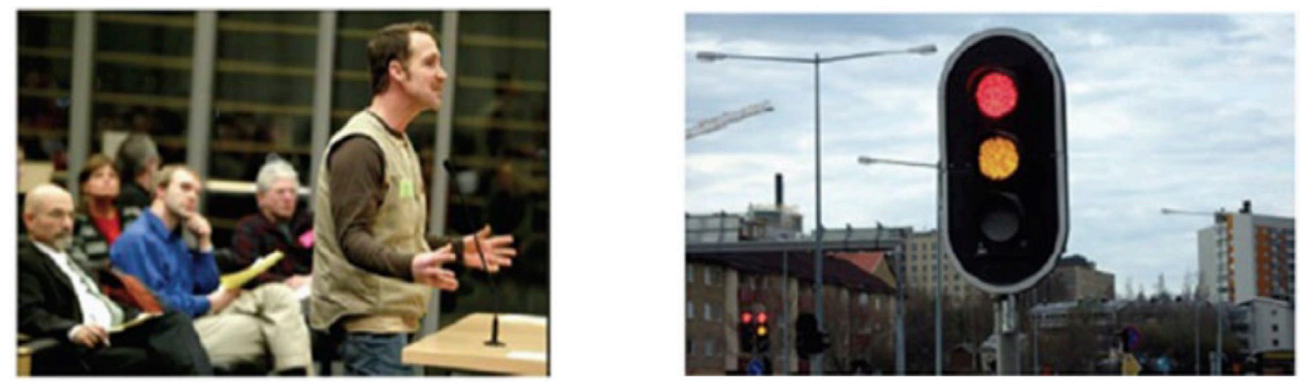

Traffic signal bond policy adopted. Kevin Bain, President of GL Homes, Inc., (left) makes a statement at Broomfield County Safety Commission meeting on surety bond policy. The Commission approved a policy that would require developers to post a bond to cover the cost of installing traffic lights (right) at development sites after construction is concluded. (Credit: Harry Stevens.)

FIGURE 3 | Control article about funding for traffic lights free of cultural framing. Adapted from Kahan et al. (2015).

then answered questions about the perceived validity of the Nature Science article.

\section{Analysis}

First, we assessed the reliability of all study variables using the criteria of Cronbach's Alpha >0.70 (Nunnally, 1978). Next, we employed six one-way ANOVAs to test for differences in trust in science $(\mathrm{H} 1)$, skepticism toward science $(\mathrm{H} 2)$, perceived risk of COVID-19 to human health and wellbeing (H3), beliefs in the wildlife origin of COVID-19 (H4), attitudes toward wildlife trade (H5), and perceived validity of the Nature Science article based on political ideology (conservative, liberal, or moderate). For each ANOVA, we conducted a post-hoc Tukey's multiple comparison tests to test for significant mean differences between each group. 


\section{Excerpt from: "COVID-19: The Relationship between Human and Environmental Health," Nature Science, Vol. 72 pp. 516-32 (2020):}

Over the past two decades we have seen the dangers of coronaviruses that are constantly evolving, resulting in deadly outbreaks that pose global public health threats. COVID-19 emerged in Wuhan, China, at the end of 2019, resulting in a quickly rising death toll around the world.

Initial studies suggest a common starting point for all of the infections: a seafood market in Wuhan, China. The restaurants of this market are famous for serving many types of wildlife for people to eat.

This seafood market is an example of a wet-market that sells birds, bats, snakes, rodents and other wild animals. Such wet-markets are ideal places for novel viruses to jump from wildlife to humans and create new human diseases.

Zoonotic diseases - those that pass from animals to humans - make up more than three-quarters of human diseases. And, $60 \%$ of zoonotic diseases come from wild animals. Notably, human activities, such as trade in wildlife, large-scale deforestation, and conversion of land for agriculture are increasing the risk of zoonotic diseases.

It is therefore important to learn what conditions allow diseases to jump from wildlife to people, and where wild animals are likely to have dangerous diseases. This should lead to new approaches for identifying diseases in wild animals, predicting how dangerous the diseases are, and learning how diseases move from wildlife to people.

The COVID-19 outbreak is the third instance where a coronavirus has crossed from wild animals to humans after the occurrence of SARS, and MERS outbreaks. The possibility of a fourth outbreak can be expected in the future, possibly from another human-wildlife interaction just like the wet-market in Wuhan.

As deaths from the COVID-19 pandemic grow globally, one thing is clear: as human interaction with wildlife continues to increase, we will see more outbreaks like COVID-19, and the next pandemic could be even more deadly and costly.

FIGURE 4 | Factually accurate article from a fictional 'Nature Science' academic journal highlighting the science surrounding COVID-19 without cultural framing. Generated by authors with information from Bonilla-Aldana et al. (2020), Mackenzie and Smith (2020), and Rothan and Byrareddy (2020).

Then, we tested message framing effects using multiple linear regression to predict the perceived validity of the Nature Science article based on the interaction of experimental treatments and political ideology (H6-7). Model 1 examined the main effect of framing type (technocratic, regulatory, or control) on perceived study validity of the Nature Science article. Model 2 added political ideology as a covariate. Political ideology was converted into two binary variables (liberal and moderate), with conservatives as the reference group. Model 3 included interactions between treatment and each dummy variable to determine if the impact of the experimental treatment groups varied depending on a respondent's political ideology. In each model, we controlled for gender ( $1=$ male, $2=$ female $)$ and education level [ 1 = "some high school," 2 = "high school diploma or GED," 3 = “Associate's or Bachelor's degree (BA, BS, etc.)," and $4=$ "Graduate or professional degree (MS, MBA, MD, JD, $\mathrm{PhD}$, etc.)."].

\section{RESULTS}

The trust in science $(\alpha=0.83)$, science skepticism $(\alpha=0.76)$, perceived risk of COVID-19 $(\alpha=0.82)$, belief in a COVID-19 wildlife origin $(\alpha=0.77)$, and attitudes toward restricting wildlife trade $(\alpha=0.89)$ scales all produced acceptable reliability (Table 1). The initial 4 -item scale used to measure perceived study validity initially produced low reliability $(\alpha=0.45)$. The removal of two items ("The scientists who did the study were 


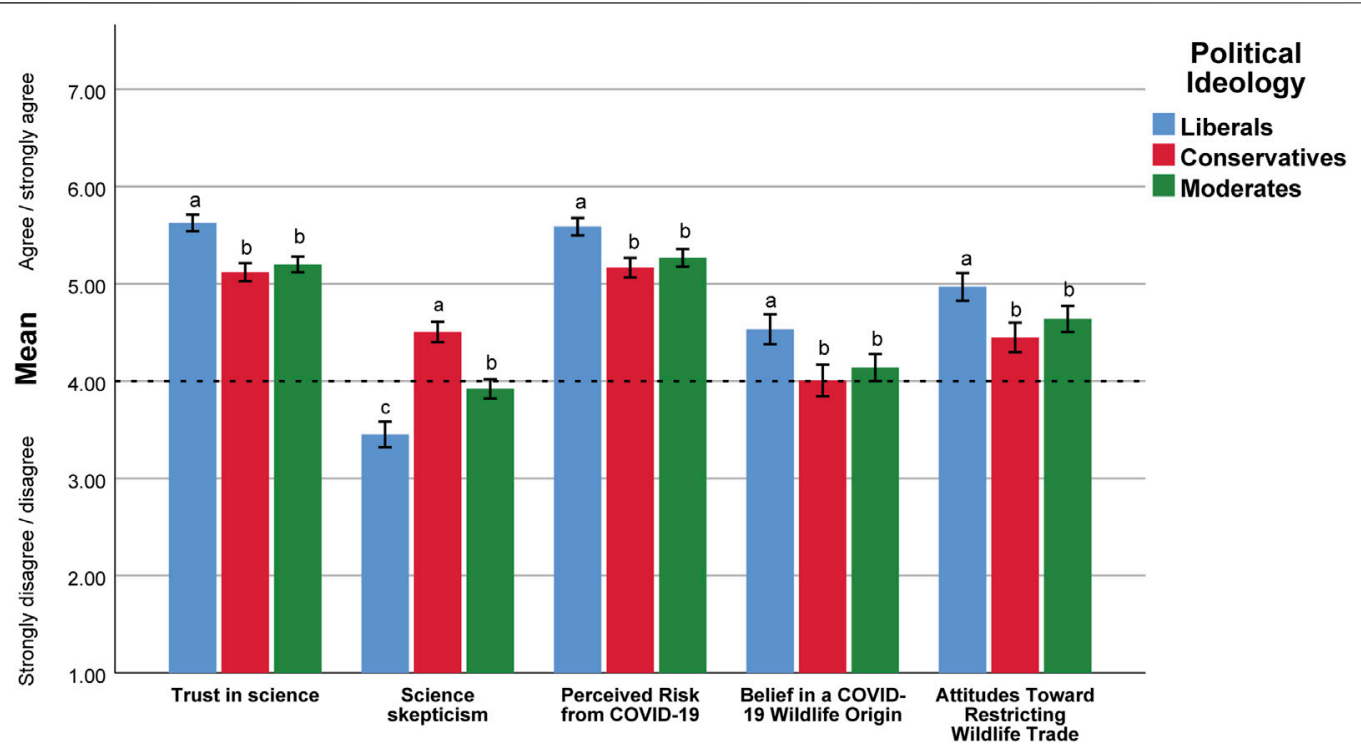

FIGURE 5 | Means with 95\% confidence intervals for study variables regarding attitudes toward science and the COVID-19 pandemic grouped by political ideology. Significant differences $(p<0.01)$ revealed by a post-hoc Tukey's Test are denoted by letters above each bar. Groups sharing the same letter are not significantly different from each other. Measured on a 7 pt Likert scale where 1 = 'strongly disagree' and 7 = 'strongly agree'. The dashed line through point 4 on the $y$-axis represents the 'neutral' choice within the 7 pt Likert Scale.

biased" and "More studies must be done before policy-makers rely on the findings of the Nature Science study") improved reliability for the final two-item scale $(\alpha=0.61)$ measuring perceived study validity (of the Nature Science article).

$\mathrm{H} 1 \mathrm{was}$ partially supported, as liberals reported higher trust in science than conservatives and moderates, but we did not detect a difference between moderates and conservatives $[F(2)=37.48$, $p<0.001$ ] (Figure 5). Similarly, H2 was partially supported, as all three groups differed significantly in their views on skepticism toward science $[F(2)=82.19, p<0.001]$. Conservatives expressed the most skepticism toward science, and liberals expressed the least (Figure 5). H3 was partially supported by the ANOVA for political ideology and perceived risk of COVID-19 $[F(2)=22.60$, $p<0.001]$. Liberals perceived more risk than both moderates and conservatives, who did not differ significantly in their views of risk (Figure 5). H4 was also partially supported by the ANOVA for COVID-19 origins $[F(2)=12.44, p<0.001]$. Liberals believed in a wildlife origin of COVID-19 more than both moderates and conservatives, who did not differ significantly (Figure 5). H5 was partially supported by the ANOVA for political ideology and wildlife trade $[F(2)=12.07, p<0.001]$. Liberals were more likely to support restrictions on wildlife trade than both conservatives and moderates, who did not differ significantly (Figure 5).

Liberals differed significantly from both conservatives and moderates in their perceived validity of the Nature Science study, and conservatives did not differ significantly from moderates $[F(2)=23.56, p<0.001]$. Mean perceived validity of the Nature Science article was highest among liberals, followed by moderates and then conservatives (Figure 5). The results of the baseline regression model, model 1 , did not detect direct effects of the technocratic $(\beta=-0.06, p=0.43)$ or regulatory framing $(\beta=0.04, p=0.59)$ on perceived study validity, and
TABLE 2 | Means and standard deviations for the perceived study validity variable by message framing treatment group and political ideology.

\begin{tabular}{llccc}
\hline Treatment & Political ideology & Mean & SD & N \\
\hline Technocratic framing & Conservatives & 5.00 & 1.38 & 169 \\
& Liberals & 5.19 & 1.08 & 163 \\
& Moderates & 5.01 & 0.99 & 191 \\
& Total & 5.06 & 1.16 & 523 \\
Regulatory framing & Conservatives & 4.87 & 1.18 & 160 \\
& Liberals & 5.50 & 1.10 & 173 \\
& Moderates & 5.16 & 1.10 & 176 \\
Control & Total & 5.18 & 1.15 & 509 \\
& Conservatives & 4.90 & 1.19 & 169 \\
& Liberals & 5.50 & 1.13 & 161 \\
& Moderates & 4.98 & 1.07 & 192 \\
& Total & 5.12 & 1.16 & 522 \\
\hline
\end{tabular}

accounted for $4 \%$ of the variation in perceived study validity $\left(R^{2}=\right.$ 0.040). Mean values showed that, across all political groups, individuals exposed to the regulatory framing perceived only slightly higher study validity than individuals exposed to the control or technocratic group (Table 2). Model 2 included the dummy variables for political ideology without any interactions and accounted for $7.2 \%$ of the variation in perceived validity of the Nature Science study $\left(R^{2}=0.072\right)$. Results revealed that liberals $(\beta=0.52, p<0.001)$ and moderates $(\beta=0.20, p=$ 0.003 ) found the Nature Science study more valid than conservatives. Model 3 examined the interaction between political ideology and each framing treatment, and accounted for approximately $7.6 \%$ of the variation in perceived study validity $\left(R^{2}=0.076\right)$ (Table 3$)$. A significant interaction between the technocratic framing and the liberal dummy 
TABLE 3 | Multiple regression modeling the effects of political ideology and treatment group on perceived study validity of the Nature Science article.

\begin{tabular}{lccc} 
Effect & Model 1 & Model 2 & Model 3 \\
\hline Intercept & $4.72(28.61)^{\star \star \star}$ & $4.58(27.38)^{\star \star \star}$ & $4.55(25.75)^{\star \star \star}$ \\
Gender & $-0.17(-2.82)^{\star \star}$ & $-0.22(-3.71)^{\star \star \star}$ & $-0.21(-3.53)^{\star \star}$ \\
Education & $0.23(6.23)^{\star \star \star}$ & $0.22(6.03)^{\star \star \star}$ & $0.22(6.03)^{\star \star \star}$ \\
Technocratic & $-0.06(-0.78)$ & $-0.06(-0.81)$ & $0.07(0.58)$ \\
Regulatory & $0.04(0.55)$ & $0.03(0.36)$ & $-0.03(-0.27)$ \\
Liberal & - & $0.52(7.27)^{\star \star \star}$ & $0.63(5.14)^{\star \star \star}$ \\
Moderate & - & $0.20(2.94)^{\star \star}$ & $0.17(1.45)$ \\
Technocratic x liberal & - & - & $-0.36(-2.08)^{\star}$ \\
Regulatory $\times$ liberal & - & - & $0.02(0.11)$ \\
Technocratic $\times$ moderate & - & - & $-0.04(-0.23)$ \\
Regulatory $\times$ moderate & - & - & $0.14(0.82)$ \\
$R^{2}$ & 0.040 & 0.072 & 0.076 \\
\hline
\end{tabular}

$\mathrm{n}=1,554$. The dependent variable is study validity. Regression weights are standardized beta coefficients with $t$-values listed in parentheses.

${ }^{*} p<0.05,{ }^{* *} p<0.01,{ }^{* * *} p<0.001$.

variable $(\beta=-0.36, p=0.05)$ partially supported H6. The plot of the interaction effect suggests that liberals who received the technocratic framing found the study less valid than the control group, and conservatives who received the technocratic framing found the study slightly more valid than the control group (Figure 6). We did not detect a significant interaction between the moderate dummy variable and the technocratic framing $(\beta=-0.04, p=0.82)$. This is also reflected in Figure 6, as moderates did not appear to differ in their perceived study validity between the group that received the technocratic framing and the one that received the control. H7 was not supported, as we did not detect a significant interaction effect on perceived study validity for the regulatory framing for the liberal dummy variable $(\beta=0.02, p=0.92)$ or the moderate dummy variable $(\beta=0.14, p=0.41)$.

\section{DISCUSSION}

Our results suggest political ideologies predict divergent views of scientific evidence (in general) and evidence about surrounding the wildlife origins of COVID-19 (specifically) in the United States. The patterns we observed build on prior research. Namely, liberals trusted science more and were less skeptical of science than both conservatives and moderates. This finding aligns with the trend of conservatives expressing less trust in science as science becomes more politicized over time (Gauchat, 2012; Nisbet et al., 2015; Funk et al., 2019). Liberals also perceived more risk from COVID-19 than conservatives and moderates, which aligns with another study suggesting conservatism was associated with less perceived individual vulnerability to COVID-19 and lower perceived severity of the pandemic (Calvillo et al., 2020). Our study also elucidates how political ideology influences topics relevant to the novel coronavirus by showing that liberals, on average, reported believing in a COVID-19 wildlife origin and supporting restrictions on wildlife trade to combat zoonotic disease more than conservatives and moderates. These results align with and reinforce initial reports that conservatives are more likely to believe conspiracy theories that COVID-19 was produced in a laboratory setting (Jiang et al., 2020; Romer and Jamieson, 2020). Together, these findings are crucial for assisting policymaking in the era of COVID-19, as policy development surrounding the

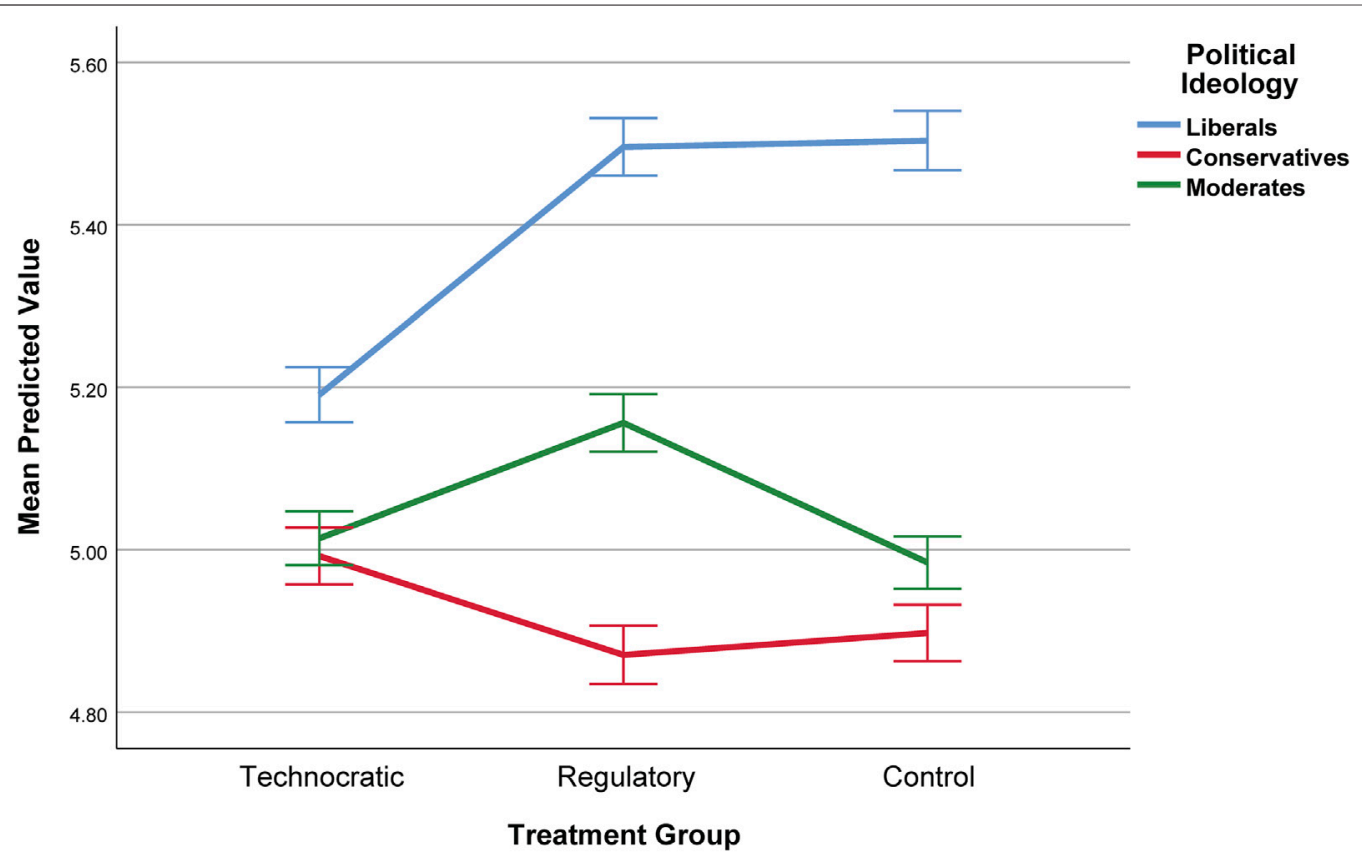

FIGURE 6 |Predicted means based on OLS regression model 3 with 95\% confidence interval error bars for perceived validity of the Nature Science study, grouped by political ideology and treatment group. 
disease will hinge on trust in scientific expertise and decisionmakers advocating for disease management (Cairney and Wellstead, 2020). They also underscore the importance of developing strategies for effectively communicating in a way that increases the perceived validity of science surrounding the pandemic, especially when politicians are inclined to use uncertainty and misinformation that appeals to political ideologies to reduce support for science-based policies (Cinelli et al., 2020; Kreps and Kriner, 2020).

Our results also contribute to research on communicating about zoonotic disease through the One Health lens by highlighting how cultural cognitions shape public consumption of related science (Kahan et al., 2011). Our investigation of different message frames related to the zoonotic origins of COVID-19 yielded two key conclusions. First, strategic framing based on cultural worldviews likely shapes how people in the United States respond to COVID-19 science, but with relatively small impacts. For instance, technocratic framing was only slightly effective in increasing perceived study validity among those with conservative ideology (as compared to conservatives in the control group). However, we did detect a significant drop in perceived study validity for liberals who received the technocratic framing as compared to those in the control group. These results are comparable to those of a study employing cultural worldviews to understand perceptions of climate change. Kahan et al. (2015) found that the technocratic framing (a framing that highlighted a geoengineering approach to climate change) increased perceived study validity among those with individualistic worldviews and decreased it among communitarians. In another study, cultural worldview influenced perceived benefits and risk of nanotechnology, with communitarians less likely than individualists to recognize the benefits of nanotechnology as compared to the risks (Kahan et al., 2008). Similarly, our results suggest that cultural appeals rooted in technological framings may negatively influence perceptions of COVID-related messaging for those with a liberal ideology. Liberals' apparent distrust of the technocratically framed article may be explained by the cultural cognition thesis, which posits that those who hold communitarian values, including political liberals, are more concerned about technological risks than more conservative people (Douglas and Wildavsky, 1983; Kahan et al., 2008). This idea has been supported by studies in the domains of nanotechnology (Kahan et al., 2008), nuclear power (Peters and Slovic, 1996), and genetically modified foods (Finucane, 2002). Thus those with liberal ideology are likely skeptical of the safety and efficacy of technological solutions to wildlife diseases due to cultural cognition. If issues surrounding science continue to be politicized in the coming years, or grow even more politicized as some predict (Gauchat, 2012; Funk et al., 2019), an enhanced understanding of the effects of cultural cognition on information processing will be crucial to improve the efficacy of science communication and inform research and practice.
The absence of an interaction between regulatory framing and political identity in the context of COVID-19 should be interpreted with caution. As implied above, among conservatives, regulatory framing may not differentially impede trust or trigger distrust in the science surrounding zoonoses in the way that it does for potentially more politically charged domains such as climate change (Kahan et al., 2015). For liberals, the regulatory framing of the study treatment might not have adequately activated communitarian values, thereby generating a negligible response. The novelty of the COVID-19 pandemic may play a role here as well, as members of the public may be less inclined to acknowledge direct links between human health and environmental conservation. New message frames that incorporate more diverse aspects of One Health communication, including those that highlight the importance of habitat conservation as a disease mitigation strategy (Deem et al., 2001), might be more effective at influencing the behavior of liberal audiences.

Our results suggest the regulatory and technocratic framings had little to no effect among self-identified moderates. This may be a result of the message content or a result of the political ideology of those in the moderate group. Unlike politicized and polarized topics such as climate change, zoonoses may be a neutral subject among moderates. Studies have also suggested that the moderate label is a poor indicator of politically central ideals. Instead, some researchers argue the self-reported moderate label is a result of respondents attempting to describe their preferences on a single scale, when in reality they prefer a mix of policies that span the political spectrum (Ahler and Broockman, 2014). This conglomeration of diverse views may drown out differences that exist within the group. Collectively, these findings regarding the influence of cultural cognition and political ideology suggest that science communicators should carefully consider the political leanings of target audiences when framing information regarding zoonotic diseases, especially within the context of the COVID-19 pandemic.

Another aspect of our study that should be noted was that, despite statistical significance, the interaction term in our model displayed low predictive power. This leads to our second conclusion that although politically motivated message framing is important when communicating about science topics, such framing might be less relevant in the case of zoonotic diseases. While strategic framing is undoubtedly influential, direct and descriptive zoonotic disease communication frames that intentionally avoid activation of cultural cognitions and values may ultimately be the safest (i.e., less polarizing and contentious) approach to influencing the beliefs and behaviors of politically diverse audiences. One possible explanation for the relatively small influence of framing and political ideology in our study is that discussions of the zoonotic origins of COVID-19 were quickly marginalized when the media began to focus myopically on polarizing issues (Hart et al., 2020) such as mask wearing (Utych, 2020) and vaccines (Puri et al., 2020). 


\section{Limitations and Future Research}

One of the primary limitations associated with this study was the possibility of omitted variable bias. Given the relatively low explanatory power of our final model, there are likely other key variables contributing to the perceived validity of the Nature Science article that were not included. For example, profession be relevant if individuals who are trained as scientists or health professionals are more likely to trust science (Krause et al., 2019), and exposure to COVID-19 could be relevant if those who have experienced the disease are more likely to believe the science of it. Initial results suggest that the lived experience of nurses during COVID-19 influenced their mental state by inducing fear, stress, and anxiety (Karimi et al., 2020). Furthermore, obese individuals reported experiencing fear and anxiety because of the pandemic and their status as a vulnerable population (Grannell et al., 2020). Future research should seek to illuminate how the lived experience of the COVID-19 virus, especially for those strongly affected by it or vulnerable to it, influences cultural cognitions.

Another limitation of this study is the use of a sample of United States respondents. The generalizability of these results cannot be assumed for an international audience. Future research should examine how cultural worldviews influence science communication about zoonoses in other countries beyond the United States where the split between political groups may be different. Specifically, liberal and conservative ideologies do not parallel political parties in other international contexts as closely as they do in the United States, where they have become seemingly inseparable (Pew Research Center, 2017). For example, eight distinct political groups across a wide ideological spectrum held seats in the European Parliament in 2019 (Pew Research Center, 2019). Nevertheless, various forms of political polarization and conflicting ideologies abound globally and consistently present challenges for effective communication (Carothers and O'Donohue, 2019). This underscores the importance of understanding cultural cognitions, however they manifest, to inform strategic communication and messaging around contentious issues such as COVID-19.

Another notable limitation is that our two-item scale for "perceived validity" of our fictional Nature Science communication failed to produce a reliability coefficient above the recommended cutoff of $\alpha=0.70$ (Nunnally, 1978). The two items we removed from the scale were reverse-coded and later recoded to match the positive wording of the other items. Scales using reverse-coded items reduce acquiescence bias, but also reduce reliability scores (Weems and Onwuegbuzie, 2001; Boley et al., 2020). The use of scale measures that were all positively worded may improve scale reliability in the future. Additionally, we closely adapted our fictional message frames from Kahan et al. (2015), which could be problematic if COVID-19 requires a drastically different approach to communication compared to other issues such as climate change. Specifically, the cultural meanings associated with COVID-19, and the mechanisms for best evoking them, are not yet well understood.

Another possible limitation for this study is self-report accuracy. While the wordings and questions were designed to be as clear as possible, some individuals might have found some questions or concepts confusing and responded inaccurately. Social desirability bias could come into play for questions regarding trust in science, assuming the respondent considers trust in science to be a socially desirable trait. However, social desirability bias may be less prominent in web (vs. face-to-face) surveys (Heerwegh, 2009). Another limitation is the use of online respondents, who are sometimes considered a less reliable source of data. However, due to the need for safe and rapid data collection, an online panel was the best option for this study as it comes close to national probability samples in terms of representativeness (Boas et al., 2018).

Future research should explore additional variables that may impact the perception of validity of scientific studies and explore the efficacy of alternative communication framings that might not be politically motivated. Gain and loss framing (Tversky and Kahneman, 1981), which can be influential in a conservation context (Jacobson et al., 2019), could be especially relevant to the COVID-19 pandemic, where the gains (lockdowns ending sooner, businesses reopening), and losses (deaths of loved ones, economic impacts) of behaviors to reduce the impact of the virus may be particularly salient. Future studies could also examine how the impacts of framing change over time, and how the efficacy of framings might differ as a function of the severity of the pandemic.

Finally, the fact that political ideology did not contribute to a large amount of variance in our model may be an artifact of the novelty and newfound salience of zoonoses in the domain of public science communication. Whereas media coverage of the origins of COVID-19 cast a relatively new spotlight on zoonotic disease, public and highly politicized debates about climate change have been simmering in the media for decades (Brulle et al., 2012). For many issues (e.g., climate change), confirmation bias compels individuals to process scientific information in ways that align with culturally congruent worldviews (Kahan et al., 2015). For respondents who have little previous experience with the concept of zoonoses, however, there may be no (or few) preexisting beliefs to confirm. Strategic communication in this context might be even more effective because heuristics that often bias interpretation of information are absent (Akin and Landrum, 2017). Disease management communication would benefit from future research examining how the United States news media, social media, and misinformation interact with cultural cognitions to influence perceptions of zoonotic disease.

\section{Conclusions}

Our results reinforce that wildlife management agencies and conservation organizations operate in an increasingly complex social and political environment, where they must consider nuanced values and worldviews in developing and communicating policy and management decisions (Manfredo 
et al., 2018). Furthermore, wildlife management is increasingly connected to broader issues and debates, presenting both potential opportunities and pitfalls. Given that zoonotic disease does not appear to be as controversial as other topics such as climate change, there may be space for wildlife agencies to proactively communicate about positive actions they are taking to help prevent occurrence and spread. For example, the United States Fish and Wildlife Service examines international shipments at ports across the country to prevent illegal transportation of animals and plants, which can help prevent the spread of wildlife diseases (U.S. Fish and Wildlife Service, 2019). Messaging that highlights these types of actions could align well with One Health communication initiatives and help wildlife management agencies proactively demonstrate the wide range of benefits that conservation can provide (Kellert et al., 2017). Effective science communication might also influence individual action to prevent the rise of zoonoses, as human interaction with wildlife is a key emergence factor (Alexander and McNutt, 2010). Inspired by One Health, interventions might involve partnerships between wildlife management (e.g., USFWS) and public health agencies (e.g., CDC) to provide proactive messaging about strategies for preventing zoonotic disease, such as keeping distances from wildlife and discouraging the purchasing of wildlife pets that may carry diseases (Chomel et al., 2007).

Our findings also highlight the importance of deploying effective communication framing that takes into account individuals' cultural values and political ideologies, especially as it pertains to topics such as zoonotic disease and politicized issues such as COVID-19. Emerging framings surrounding the risk of zoonoses that emphasize regulation, including the One Health framing, have the potential to generate backlash with conservatives (Wildavsky, 1987; Kahan et al., 2008; Kahan et al., 2015), though we did not detect this effect in the present study. In particular, regulations on wildlife trade and movements to expand protected areas to minimize the threat of zoonoses, though promising from a One Health perspective (Jenkins et al., 2015; Bonilla-Aldana et al., 2020), may be met with resistance among groups with individualistic values (Kahan et al., 2011). Our results highlight a potential to improve the efficacy of message frames directed at conservative audiences by focusing instead on feats of human ingenuity used to manage wildlife disease. Content in this messaging might include disease tracing, culling of diseased animals, and vaccination of wildlife populations (Bosch et al., 2015; Grant et al., 2017), or just a purely descriptive communication of the science of wildlife disease management. However, future research is needed to clarify how conservatives respond to different forms of regulatory framing in the context of COVID-19 and how this might change over time. Some wildlife management agencies may already be experiencing a backlash against policies and actions that seek to broaden conservation agendas beyond a historic focus on game species (Manfredo et al., 2017). In these cases, strategic framing may have the potential to influence conservatives' perceived validity of the science, which may enhance support for policy measures taken to prevent zoonotic diseases from emerging and spreading (Hanisch-Kirkbride et al., 2013).
On the other hand, technocratic solutions rooted in human ingenuity are not the only factors needed to effectively prevent the emergence and spread of zoonoses (Langwig et al., 2015). In fact, overemphasis on these approaches might be unpalatable to those with liberal and communitarian ideologies. Therefore, communication aimed at liberal audiences might focus on broader conservation goals while avoiding discussing tactics such as culling populations of threatened or endangered wildlife (Nugent, 2011; White et al., 2011; van Herten et al., 2019). Ultimately, a combination of these approaches is likely needed to effectively connect with different audiences and reduce the threat of zoonotic global outbreaks such as COVID-19 (Bosch et al., 2015; Cunningham, et al., 2017; Grant et al., 2017). Such dilemmas highlight the growing importance of risk communication surrounding zoonotic disease and the need for strategic messaging to target distinct populations in order to achieve collective management goals and reduce the impacts of future pandemics on human health and environmental health.

\section{DATA AVAILABILITY STATEMENT}

The datasets presented in this article are not readily available because IRB restricts the distribution of data related to human subjects. Requests to access the datasets should be directed to Justin Beall, jmbeall@ncsu.edu.

\section{ETHICS STATEMENT}

The studies involving human participants were reviewed and approved by North Carolina State University Institutional Review Board for the Use of Human Subjects in Research. Written informed consent for participation was not required for this study in accordance with the national legislation and the institutional requirements.

\section{AUTHOR CONTRIBUTIONS}

JB contributed much of the writing for this publication, performed the analysis, and helped design the survey instrument. WC contributed to the analysis and development of the survey instrument. He also helped with comments and direct contributions to the writing. MP took the lead on the design of the study and contributed significantly to the writing of the manuscript. LL was also heavily involved with study design and the writing of the manuscript. He also helped with analysis. WC contributed heavily to the portion of the discussion surrounding practical implications of our study and gave feedback to survey design. ES contributed feedback during the development of the survey and offered both comments and direct contributions during the writing process. KS contributed feedback during the development of the survey and offered both comments and direct contributions during the writing process. SJ 
contributed feedback during the development of the survey, helped with the survey distribution process, and provided comments, direct contributions, and edits during the writing process.

\section{FUNDING}

This research was funded by Grant No. G15AP00162 from the U.S. Geological Survey Southeast Climate Adaptation Science Center, which is managed by the USGS National Climate Adaptation Science Center.

\section{REFERENCES}

Ahler, D. J., and Broockman, D. E. (2014). How Ideological Moderation Conceals Support For Immoderate Policies: A New Perspective On the 'Disconnect' in American Politics. Working Paper. Berkeley, CA, United States: Institute of Governmental Studies, University of California-Berkeley.

Akin, H., and Landrum, A. R. (2017). A Recap: Heuristics, Biases, Values, and other Challenges to Communicating Science. New York, NY, United States: The Oxford Handbook of the Science of Science Communication, 455-460. doi:10.1093/oxfordhb/9780190497620.013.48

Alexander, K. A., and McNutt, J. W. (2010). Human Behavior Influences Infectious Disease Emergence at the Human-Animal Interface. Front. Ecol. Environ. 8 (10), 522-526. doi:10.1890/090057

Andersen, K. G., Rambaut, A., Lipkin, W. I., Holmes, E. C., and Garry, R. F. (2020). The Proximal Origin of SARS-CoV-2. Nat. Med. 26 (4), 450-452. doi:10.1038/ s41591-020-0820-9

Ang, B. S. P., Lim, T. C. C., and Wang, L. (2018). Nipah Virus Infection. J. Clin. Microbiol. 56 (6), e01875-17. doi:10.1128/jcm.01875-17

Boas, T. C., Christenson, D. P., and Glick, D. M. (2018). Recruiting Large Online Samples in the united states and india: Facebook, Mechanical Turk, and Qualtrics. Psrm 8 (2), 232-250. doi:10.1017/psrm.2018.28

Boley, B. B., Jordan, E., and Woosnam, K. M. (2020). Reversed Polarity Items in Tourism Scales: Best Practice or Dimensional Pitfall? Curr. Issues Tourism 24, 466-478. doi:10.1080/13683500.2020.1774517

Bonilla-Aldana, D. K., Dhama, K., and Rodriguez-Morales, A. J. (2020). Revisiting the One Health Approach in the Context of COVID-19: A Look into the Ecology of This Emerging Disease. Adv. Anim. Vet. Sci. 8 (3), 234-237. doi:10. 17582/journal.aavs/2020/8.3.234.237

Bosch, J., Sanchez-Tomé, E., Fernández-Loras, A., Oliver, J. A., Fisher, M. C., and Garner, T. W. J. (2015). Successful Elimination of a Lethal Wildlife Infectious Disease in Nature. Biol. Lett. 11, 20150874. doi:10.1098/rsbl.2015.0874

Brulle, R. J., Carmichael, J., and Jenkins, J. C. (2012). Shifting Public Opinion on Climate Change: an Empirical Assessment of Factors Influencing Concern over Climate Change in the U.S., 2002-2010. Climatic Change 114 (2), 169-188. doi:10.1007/s10584-012-0403-y

Bussani, R., Schneider, E., Zentilin, L., Collesi, C., Ali, H., Braga, L., et al. (2020). Persistence of Viral RNA, Pneumocyte Syncytia and Thrombosis Are Hallmarks of Advanced COVID-19 Pathology. EBioMedicine 61, 103104. doi:10.1016/j.ebiom.2020.103104

Buttke, D. E., Decker, D. J., and Wild, M. A. (2015). The Role of One Health in Wildlife Conservation: a challenge and Opportunity. J. Wildl. Dis. 51 (1), 1-8. doi:10.7589/2014-01-004

Cahan, E. (2020). COVID-19 Hits U.S. Mink Farms after Ripping through Europe. Science. doi:10.1126/science.abe 3870

Cairney, P., and Wellstead, A. (2020). COVID-19: Effective Policymaking Depends on Trust in Experts, Politicians, and the Public. Pol. Des. Pract. 4 (1), 1-14. doi:10.1080/25741292.2020.1837466

Calvillo, D. P., Ross, B. J., Garcia, R. J. B., Smelter, T. J., and Rutchick, A. M. (2020). Political Ideology Predicts Perceptions of the Threat of COVID-19 (And Susceptibility to Fake News about it). Soc. Psychol. Personal. Sci. 11 (8), 1119-1128. doi:10.1177/1948550620940539

\section{ACKNOWLEDGMENTS}

We would like to thank Mallory Martin at the U.S. Fish and Wildlife Service for his thoughtful comments about the survey instrument and study.

\section{SUPPLEMENTARY MATERIAL}

The Supplementary Material for this article can be found online at: https://www.frontiersin.org/articles/10.3389/fcomm.2021.645692/ full\#supplementary-material

T. Carothers and A. O'Donohue (2019). Democracies Divided: The Global challenge of Political Polarization (Washington, D.C., United States: Brookings Institution Press).

Casola, W. R., Rushing, J., Futch, S., Vayer, V., Lawson, D. F., Cavalieri, M. J., et al. (2020). How Do YouTube Videos Impact Tolerance of Wolves? Hum. Dimensions Wildl., 25, 531-543. doi:10.1080/10871209.2020. 1773582

Centers for Disease Control (2018). Emerging Infectious Diseases. Available at: https://www.cdc.gov/niosh/topics/emerginfectdiseases/default.html\#: :text= Emerging\%20infectious\%20diseases\%20are\%20those,increase\%20in\%20the $\% 20$ near\%20future [Accessed December 16, 2020].

Centers for Disease Control (2020). One Health. Available at: https://www.cdc.gov/ onehealth/ [Accessed December 1, 2020].

Centers for Systems Science and Engineering (2020). COVID-19 Dashboard by the Center for Systems Science and Engineering (CSSE) at Johns Hopkins University (JHU). Available at: https://coronavirus.jhu.edu/map.html [Accessed December 20, 2020].

Chomel, B. B., Belotto, A., and Meslin, F.-X. (2007). Wildlife, Exotic Pets, and Emerging Zoonoses1. Emerg. Infect. Dis. 13 (1), 6-11. doi:10.3201/eid1301. 060480

Cinelli, M., Quattrociocchi, W., Galeazzi, A., Valensise, C. M., Brugnoli, E., Schmidt, A. L., et al. (2020). The Covid-19 Social media Infodemic. Sci. Rep. 10 (1), 1-10. doi:10.1038/s41598-020-73510-5

Corlett, R. T., Primack, R. B., Devictor, V., Maas, B., Goswami, V. R., Bates, A. E., et al. (2020). Impacts of the Coronavirus Pandemic on Biodiversity Conservation. Biol. Conservation 246, 108571. doi:10.1016/j.biocon.2020. 108571

Cunningham, A. A., Daszak, P., and Wood, J. L. N. (2017). One Health, Emerging Infectious Diseases and Wildlife: Two Decades of Progress? Phil. Trans. R. Soc. B 372, 20160167. doi:10.1098/rstb.2016.0167

Cutler, D. M., and Summers, L. H. (2020). The COVID-19 Pandemic and the $\$ 16$ Trillion Virus. Jama 324 (15), 1495-1496. doi:10.1001/jama.2020.19759

Daszak, P., Cunningham, A., and Hyatt, A. (2000). Emerging Infectious Diseases of Wildlife-- Threats to Biodiversity and Human Health. Science (American Association for the Advancement of Science) 287 (5452), 443-449. doi:10. $1126 /$ science. 287.5452 .443

Decker, D. J., Siemer, W. F., Evensen, D. T., Stedman, R. C., McComas, K. A., Wild, M. A., et al. (2012). Public Perceptions of Wildlife-Associated Disease: Risk Communication Matters. Human-Wildlife Interactions 6 (1), 112-122. https:// www.jstor.org/stable/24874082

Deem, S. L., Karesh, W. B., and Weisman, W. (2001). Putting Theory into Practice: Wildlife Health in Conservation. Conservation Biol. 15 (5), 1224-1233. doi:10. 1111/j.1523-1739.2001.00336.x10.1046/j.1523-1739.2001.00336.x

Dong, E., Du, H., and Gardner, L. (2020). An Interactive Web-Based Dashboard to Track COVID-19 in Real Time. Lancet Infect. Dis. 20 (5), 533-534. doi:10.1016/ S1473-3099(20)30120-1

Douglas, M., and Wildavsky, A. (1983). Risk and Culture: An Essay on the Selection of Technological and Environmental Dangers. Berkeley and Los Angeles, CA, United States: Univ of California Press. doi:10.1525/9780520907393

Evans, T., Olson, S., Watson, J., Gruetzmacher, K., Pruvot, M., Jupiter, S., et al. (2020). Links between Ecological Integrity, Emerging Infectious Diseases Originating from Wildlife, and Other Aspects of Human Health-An 
Overview of the Literature. New York: Wildlife Conservation Society. doi:10. 13140/rg.2.2.34736.5120510.19121/2020.report.37426

Finucane, M. L. (2002). Mad Cows, Mad Corn and Mad Communities: The Role of Socio-Cultural Factors in the Perceived Risk of Genetically-Modified Food. Proc. Nutr. Soc. 61, 31-37. doi:10.1079/PNS2001127

Fonkwo, P. N. (2008). Pricing Infectious Disease. EMBO Rep. 9 (S1), S13-S17. doi:10.1038/embor.2008.110

Funk, C., Hefferon, M., Kennedy, B., and Johnson, C. (2019). Trust and Mistrust in Americans' Views of Scientific Experts. Washington, D.C., United States: Pew Research Center.

Gastil, J., Braman, D., Kahan, D., and Slovic, P. (2011). The Cultural Orientation of Mass Political Opinion. Apsc 44 (4), 711-714. doi:10.1017/S1049096511001326

Gauchat, G. (2011). The Cultural Authority of Science: Public Trust and Acceptance of Organized Science. Public Underst Sci., (Bristol, England): Public Understanding of Science, 20 (6), 751-770. doi:10.1177/ 0963662510365246

Gauchat, G. (2012). Politicization of Science in the Public Sphere. Am. Sociol. Rev. 77 (2), 167-187. doi:10.1177/0003122412438225

George, T. L., Harrigan, R. J., LaManna, J. A., DeSante, D. F., Saracco, J. F., and Smith, T. B. (2015). Persistent Impacts of West Nile Virus on north American Bird Populations. Proc. Natl. Acad. Sci. USA 112 (46), 14290-14294. doi:10. 1073/pnas.1507747112

Global Preparedness Monitoring Board (2019). World at Risk: Annual Report on Global Preparedness for Health Emergencies. Geneva: World Health Organization.

Grannell, A., Roux, C. W., and McGillicuddy, D. (2020). "I Am Terrified of Something Happening to $\mathrm{Me}$ " the Lived Experience of People with Obesity during the COVID -19 Pandemic. Clin. Obes. 10 (6), e12406. doi:10.1111/cob. 12406

Grant, E. H. C., Muths, E., Katz, R. A., Canessa, S., Adams, M. J., Ballard, J. R., et al. (2017). Using Decision Analysis to Support Proactive Management of Emerging Infectious Wildlife Diseases. Front. Ecol. Environ. 15 (4), 214-221. doi:10.1002/fee.1481

Hamilton, L. (2015). Conservative and Liberal Views of Science, Does Trust Depend on Topic? The Carsey Sch. Public Pol. Scholars' Repository 252, 1-10. doi:10.34051/p/2020.242

Hanisch-Kirkbride, S. L., Riley, S. J., and Gore, M. L. (2013). Wildlife Disease and Risk Perception. J. Wildl. Dis. 49 (4), 841-849. doi:10.7589/2013-02-031

Hart, P. S., Chinn, S., and Soroka, S. (2020). Politicization and Polarization in COVID-19 News Coverage. Sci. Commun. 42 (5), 679-697. doi:10.1177/ 1075547020950735

Heerwegh, D. (2009). Mode Differences between Face-To-Face and Web Surveys: an Experimental Investigation of Data Quality and Social Desirability Effects. Int. J. Public Opin. Res. 21 (1), 111-121. doi:10. 1093/ijpor/edn054

Henig, R. M. (2020). To End This Pandemic We Must Trust Science. National Geographic. Available at: https://www.nationalgeographic.com/magazine/ 2020/11/to-end-this-pandemic-we-must-trust-science-feature/ (Accessed December 10, 2020).

Jacobson, S. K., Morales, N. A., Chen, B., Soodeen, R., Moulton, M. P., and Jain, E. (2019). Love or Loss: Effective Message Framing to Promote Environmental Conservation. Appl. Environ. Educ. Commun. 18 (3), 252-265. doi:10.1080/ 1533015x.2018.1456380

Jenkins, E. J., Castrodale, L. J., de Rosemond, S. J. C., Dixon, B. R., Elmore, S. A., Gesy, K. M., et al. (2013). Tradition and Transition. Adv. Parasitol. 82, 33-204. doi:10.1016/B978-0-12-407706-5.00002-2

Jenkins, E. J., Simon, A., Bachand, N., and Stephen, C. (2015). Wildlife Parasites in a One Health World. Trends Parasitol. 31 (5), 174-180. doi:10.1016/j.pt.2015. 01.002

Jiang, J., Chen, E., Yan, S., Lerman, K., and Ferrara, E. (2020). Political Polarization Drives Online Conversations aboutCOVID-19 in the United States. Hum. Behav Emerg Tech 2 (3), 200-211. doi:10.1002/hbe2.202

Kahan, D. M., Braman, D., Slovic, P., Gastil, J., and Cohen, G. (2008). Cultural Cognition of the Risks and Benefits of Nanotechnology. Nat. Nanotech 4 (2), 87-90. doi:10.1038/nnano.2008.341

Kahan, D. M., Braman, D., Monahan, J., Callahan, L., and Peters, E. (2010). Cultural Cognition and Public Policy: The Case of Outpatient Commitment Laws. L. Hum. Behav. 34 (2), 118-140. doi:10.1007/s10979-008-9174-4
Kahan, D. M., Jenkins-Smith, H., and Braman, D. (2011). Cultural Cognition of Scientific Consensus. J. Risk Res. 14 (2), 147-174. doi:10.1080/13669877.2010. 511246

Kahan, D. M., Jenkins-Smith, H., Tarantola, T., Silva, C. L., and Braman, D. (2015). Geoengineering and Climate Change Polarization. Ann. Am. Acad. Polit. Soc. Sci. 658 (1), 192-222. doi:10.1177/0002716214559002

Karimi, Z., Fereidouni, Z., Behnammoghadam, M., Alimohammadi, N., Mousavizadeh, A., Salehi, T., et al. (2020). The Lived Experience of Nurses Caring for Patients with COVID-19 in Iran: a Phenomenological Study. Rmhp Vol. 13, 1271-1278. doi:10.2147/RMHP.S258785

Kellert, S. R., Case, D. J., Escher, D., Witter, D. J., Mikels-Carrasco, J., and Seng, P. T. (2017). The Nature of Americans: Disconnection and Recommendations for reconnectionThe Nature of Americans National Report. Mishawaka, Indiana, USA: DJ Case and Associates.

Krause, N. M., Brossard, D., Scheufele, D. A., Xenos, M. A., and Franke, K. (2019). The Polls-Trends. Public Opin. Q. 83 (4), 817-836. doi:10.1093/poq/nfz041

Kreps, S. E., and Kriner, D. L. (2020). Model Uncertainty, Political Contestation, and Public Trust in Science: Evidence from the COVID-19 Pandemic. Sci. Adv. 6, eabd4563. doi:10.1126/sciadv.abd4563

Langwig, K. E., Voyles, J., Wilber, M. Q., Frick, W. F., Murray, K. A., Bolker, B. M., et al. (2015). Context-dependent Conservation Responses to Emerging Wildlife Diseases. Front. Ecol. Environ. 13 (4), 195-202. doi:10.1890/140241

Lapinski, M. K., Funk, J. A., and Moccia, L. T. (2015). Recommendations for the Role of Social Science Research in One Health. Soc. Sci. Med. 129, 51-60. doi:10. 1016/j.socscimed.2014.09.048

Lu, H., McComas, K. A., Buttke, D. E., Roh, S., and Wild, M. A. (2016). A One Health Message about Bats Increases Intentions to Follow Public Health Guidance on Bat Rabies. PLoS One 11 (5), e0156205. doi:10.1371/journal. pone. 0156205

Lu, H., McComas, K. A., Buttke, D. E., Roh, S., Wild, M. A., and Decker, D. J. (2017). One Health Messaging about Bats and Rabies: How Framing of Risks, Benefits and Attributions Can Support Public Health and Wildlife Conservation Goals. Wildl. Res. 44 (3), 200-206. doi:10.1071/WR16061

MacFarlane, D., and Rocha, R. (2020). Guidelines for Communicating about Bats to Prevent Persecution in the Time of COVID-19. Biol. Conservation 248, 108650. doi:10.1016/j.biocon.2020.108650

Mackenzie, J. S., and Smith, D. W. (2020). COVID-19: A Novel Zoonotic Disease Caused by a Coronavirus from China: What We Know and what We Don't. Microbiol. Aust. 41 (1), 45-MA20013. doi:10.1071/ma20013

Manfredo, M. J., Teel, T. L., Sullivan, L., and Dietsch, A. M. (2017). Values, Trust, and Cultural Backlash in Conservation Governance: The Case of Wildlife Management in the United States. Biol. Conservation 214, 303-311. doi:10. 1016/j.biocon.2017.07.032

Manfredo, M. J., Sullivan, L., Don Carlos, A. W., Dietsch, A. M., Teel, T. L., Bright, A. D., et al. (2018). America's Wildlife Values: The Social Context of Wildlife Management in the US National Report from the Research Project Entitled "America's Wildlife Values". Fort Collins: Colorado State University, Department of Human Dimensions of Natural Resources.

Morand, S. (2020). Emerging Diseases, Livestock Expansion and Biodiversity Loss Are Positively Related at Global Scale. Biol. Conservation 248, 108707. doi:10. 1016/j.biocon.2020.108707

Munnink, B. B. O., Sikkema, R. S., Nieuwenhuijse, D. F., Molenaar, R. J., Munger, E., Molenkamp, R., et al. (2020). Transmission of SARS-CoV-2 on Mink Farms between Humans and Mink and Back to Humans. Science, 371 (6525), 172-177. doi:10.1126/science.abe5901

Nadelson, L., Jorcyk, C., Yang, D., Jarratt Smith, M., Matson, S., Cornell, K., et al. (2014). I Just Don't Trust Them: The Development and Validation of an Assessment Instrument to Measure Trust in Science and Scientists. Sch. Sci. Math. 114 (2), 76-86. doi:10.1111/ssm.12051

Nisbet, E. C., Cooper, K. E., and Garrett, R. K. (2015). The Partisan Brain. Ann. Am. Acad. Polit. Soc. Sci. 658 (1), 36-66. doi:10.1177/0002716214555474

Nugent, G. (2011). Maintenance, Spillover and Spillback Transmission of Bovine Tuberculosis in Multi-Host Wildlife Complexes: A new zealand Case Study. Vet. Microbiol. 151 (1-2), 34-42. doi:10.1016/j.vetmic.2011.02.023

Nunnally, J. C. (1978). Psychometric Theory. 2nd ed. New York: McGraw-Hill.

Nuwer, R. (2020). Nature Is Returning. Sierra Club. Available at: https://www. sierraclub.org/sierra/2020-6-november-december/feature/nature-returning-duringcovid-coronavirus-pandemic (Accessed December 10, 2020). 
Olival, K. J., Cryan, P. M., Amman, B. R., Baric, R. S., Blehert, D. S., Brook, C. E., et al. (2020). Possibility for Reverse Zoonotic Transmission of SARS-CoV-2 to Free-Ranging Wildlife: A Case Study of Bats. Plos Pathog. 16 (9), e1008758. doi:10.1371/journal.ppat.1008758

Peters, E., and Slovic, P. (1996). The Role of Affect and Worldviews as Orienting Dispositions in the Perception and Acceptance of Nuclear Power1. J. Appl. Soc. Pyschol 26, 1427-1453. doi:10.1111/j.1559-1816.1996.tb00079.x

Pew Research Center (2017). The Partisan divide on Political Values Grows Even Wider. Washington D.C., United States: Pew Research Center. Available at: https://www.pewresearch.org/politics/2017/10/05/the-partisan-divide-onpolitical-values-grows-even-wider/ (Accessed May 16, 2021).

Pew Research Center (2019). European Public Opinion Three Decades after the Fall of Communism: Most Embrace Democracy and the EU, but many Worry about the Political and Economic Future. Washington D.C., United States: Pew Research Center. Available at: https://www.pewresearch.org/global/2019/10/15/ european-public-opinion-three-decades-after-the-fall-of-communism/ (Accessed May 16, 2021).

Puri, N., Coomes, E. A., Haghbayan, H., and Gunaratne, K. (2020). Social media and Vaccine Hesitancy: New Updates for the Era of COVID-19 and Globalized Infectious Diseases. Hum. Vaccin. Immunother. 16, 2586-2593. doi:10.1080/ 21645515.2020.1780846

Roh, S., McComas, K. A., Rickard, L. N., and Decker, D. J. (2015). How Motivated Reasoning and Temporal Frames May Polarize Opinions about Wildlife Disease Risk. Sci. Commun. 37 (3), 340-370. doi:10.1177/ 1075547015575181

Romer, D., and Jamieson, K. H. (2020). Conspiracy Theories as Barriers to Controlling the Spread of COVID-19 in the U.S. Soc. Sci. Med. 263, 113356. doi:10.1016/j.socscimed.2020.113356

Rothan, H. A., and Byrareddy, S. N. (2020). The Epidemiology and Pathogenesis of Coronavirus Disease (COVID-19) Outbreak. J. Autoimmun. 109, 102433. doi:10.1016/j.jaut.2020.102433

Thompson, R. C. A. (2013). Parasite Zoonoses and Wildlife: One Health, Spillover and Human Activity. Int. J. Parasitol. 43 (12-13), 1079-1088. doi:10.1016/j. ijpara.2013.06.007

Triezenberg, H. A., Gore, M. L., Riley, S. J., and Lapinski, M. K. (2014). Persuasive Communication Aimed at Achieving Wildlife-Disease Management Goals. Wildl. Soc. Bull. 38 (4), 734-740. doi:10.1002/wsb.462

Tversky, A., and Kahneman, D. (1981). The Framing of Decisions and the Psychology of Choice. Science 211, 453-458. doi:10.1126/science.7455683

U.S. Fish and Wildlife Service (2019). About Service Wildife Inspectors. Available at: https://www.fws.gov/le/wildlife-inspectors.html [Accessed December 17th, 2020].

UNAIDS (2020). Global HIV \& AIDS Statistics - 2020 Fact Sheet. Retrieved from: https://www.unaids.org/en/resources/fact-sheet\#: :text=690\%20000\%20\%5B500\% $20000 \%$ E2\%80\%93970,the\%20start\%20of\%20the\%20epidemic [Accessed November 22, 2020].

Utych, S. M. (2020). Messaging Mask Wearing during the COVID-19 Crisis: Ideological Differences. J. Exp. Polit. Sci., 1-11. doi:10.1017/XPS.2020.15 van der Linden, S. (2016). A Conceptual Critique of the Cultural Cognition Thesis Sci. Commun. 38 (1), 128-138. doi:10.1177/1075547015614970

van Herten, J., Bovenkerk, B., and Verweij, M. (2019). One Health as a Moral Dilemma: Towards a Socially Responsible Zoonotic Disease Control. Zoonoses Public Health 66 (1), 26-34. doi:10.1111/zph.12536

Vraga, E. K., and Jacobsen, K. H. (2020). Strategies for Effective Health Communication during the Coronavirus Pandemic and Future Emerging Infectious Disease Events. World Med. Health Pol. 12 (3), 233-241. doi:10. 1002/wmh3.359

Weems, G. H., and Onwuegbuzie, A. J. (2001). The Impact of Midpoint Responses and Reverse Coding on Survey Data. Meas. Eval. Couns. Dev. 34 (3), 166-176. doi:10.1080/07481756.2002.12069033

White, P. J., Wallen, R. L., Geremia, C., Treanor, J. J., and Blanton, D. W. (2011). Management of Yellowstone bison and Brucellosis Transmission Risk Implications for Conservation and Restoration. Biol. Conservation 144 (5), 1322-1334. doi:10.1016/j.biocon.2011.01.003

Wildavsky, A. (1987). Choosing Preferences by Constructing Institutions: A Cultural Theory of Preference Formation. Am. Polit. Sci. Rev. 81 (1), 3-21. doi:10.2307/1960776

World Health Organization (2019). World Malaria Report 2019. Geneva: World Health Organization.

World Health Organization (2020). Zoonoses. Available at: https://www.who.int/ topics/zoonoses/en/ [Accessed December 3, 2020].

Wu, F., Zhao, S., Yu, B., Chen, Y.-M., Wang, W., Song, Z.-G., et al. (2020). A New Coronavirus Associated with Human Respiratory Disease in china. Nature 579 (7798), 265-269. doi:10.1038/s41586-020-2008-3

Zhou, P., Yang, X.-L., Wang, X.-G., Hu, B., Zhang, L., Zhang, W., et al. (2020). A Pneumonia Outbreak Associated with a New Coronavirus of Probable Bat Origin. Nature 579 (7798), 270-273. doi:10.1038/s41586020-2012-7

Zimmerman, H., and Eddens, A. (2018). Governing the liberal Self in a 'post-truth' Era: Science, Class and the Debate over GMOs. Cult. Stud. 32 (6), 953-974. doi:10.1080/09502386.2018.1431301

J. Zinsstag, E. Schelling, L. Crump, M. Whittaker, M. Tanner, and C. Stephen(2020). One Health: The Theory and Practice of Integrated Health Approaches (Boston, MA, United States: CABI).

Conflict of Interest: The authors declare that the research was conducted in the absence of any commercial or financial relationships that could be construed as a potential conflict of interest.

Copyright (c) 2021 Beall, Casola, Peterson, Larson, Carr, Seekamp, Stevenson and Jackson. This is an open-access article distributed under the terms of the Creative Commons Attribution License (CC BY). The use, distribution or reproduction in other forums is permitted, provided the original author(s) and the copyright owner(s) are credited and that the original publication in this journal is cited, in accordance with accepted academic practice. No use, distribution or reproduction is permitted which does not comply with these terms. 